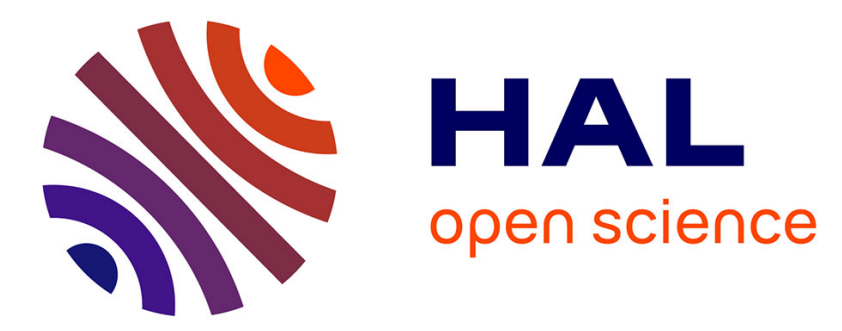

\title{
Potential impact of climate change on marine dimethyl sulfide emissions
}

\author{
Laurent Bopp, Olivier Aumont, Sauveur Belviso, Patrick Monfray
}

\section{To cite this version:}

Laurent Bopp, Olivier Aumont, Sauveur Belviso, Patrick Monfray. Potential impact of climate change on marine dimethyl sulfide emissions. Tellus B - Chemical and Physical Meteorology, 2003, 55 (1), pp.11-22. 10.3402/tellusb.v55i1.16359 . hal-03111698

\section{HAL Id: hal-03111698 \\ https://hal.science/hal-03111698}

Submitted on 15 Jan 2021

HAL is a multi-disciplinary open access archive for the deposit and dissemination of scientific research documents, whether they are published or not. The documents may come from teaching and research institutions in France or abroad, or from public or private research centers.
L'archive ouverte pluridisciplinaire HAL, est destinée au dépôt et à la diffusion de documents scientifiques de niveau recherche, publiés ou non, émanant des établissements d'enseignement et de recherche français ou étrangers, des laboratoires publics ou privés. 


\section{Tellus B: Chemical and Physical Meteorology}

\section{Potential impact of climate change on marine dimethyl sulfide emissions}

\section{Laurent Bopp, Oliver Aumont, Sauveur Belviso \& Patrick Monfray}

To cite this article: Laurent Bopp, Oliver Aumont, Sauveur Belviso \& Patrick Monfray (2003)

Potential impact of climate change on marine dimethyl sulfide emissions, Tellus B: Chemical and Physical Meteorology, 55:1, 11-22, DOI: 10.3402/tellusb.v55i1.16359

To link to this article: https://doi.org/10.3402/tellusb.v55i1.16359

$$
\begin{aligned}
& \text { (c) } 2003 \text { The Author(s). Published by Taylor \& } \\
& \text { Francis. }
\end{aligned}
$$

\section{曲 Published online: 15 Dec 2016.}

Submit your article to this journal $\pi$

Џ Article views: 193

Q View related articles $₫$

en

Citing articles: 17 View citing articles 


\title{
Potential impact of climate change on marine dimethyl sulfide emissions
}

\author{
By LAURENT BOPP ${ }^{*}$, OLIVIER AUMONT ${ }^{2}$, SAUVEUR BELVISO ${ }^{1}$ and PATRICK MONFRAY ${ }^{1}$, \\ ${ }^{1}$ Laboratoire des Sciences du Climat et de l'Environnement, Orme des Merisiers, CE Saclay, F-91191 Gif \\ sur Yvette, France; ${ }^{2}$ Laboratoire d'Océanographie et de Dynamique du Climat, Université Paris 6, F-75252 \\ Paris, France
}

(Manuscript received 23 August 2001; in final form 3 July 2002)

\begin{abstract}
Dimethyl sulfide (DMS) is a biogenic compound produced in sea-surface water and outgased to the atmosphere. Once in the atmosphere, DMS is a significant source of cloud condensation nuclei in the unpolluted marine atmosphere. It has been postulated that climate may be partly modulated by variations in DMS production through a DMS-cloud condensation nuclei-albedo feedback. We present here a modelled estimation of the response of DMS sea-water concentrations and DMS fluxes to climate change, following previous work on marine DMS modeling (Aumont et al., 2002) and on the global warming impact on marine biology (Bopp et al., 2001). An atmosphere-ocean general circulation model (GCM) was coupled to a marine biogeochemical scheme and used without flux correction to simulate climate response to increased greenhouse gases (a $1 \%$ increase per year in atmospheric $\mathrm{CO}_{2}$ until it has doubled). The predicted global distribution of DMS at $1 \times \mathrm{CO}_{2}$ compares reasonably well with observations; however, in the high latitudes, very elevated concentrations of DMS due to spring and summer blooms of Phaeocystis can not be reproduced. At $2 \times \mathrm{CO}_{2}$, the model estimates a small increase of global DMS flux to the atmosphere $(+2 \%)$ but with large spatial heterogeneities (from $-15 \%$ to $+30 \%$ for the zonal mean). Mechanisms affecting DMS fluxes are changes in (1) marine biological productivity, (2) relative abundance of phytoplankton species and (3) wind intensity. The mean DMS flux perturbation we simulate represents a small negative feedback on global warming; however, the large regional changes may significantly impact regional temperature and precipitation patterns.
\end{abstract}

\section{Introduction}

Dimethyl sulfide (DMS) is the most abundant volatile sulfur compound at the sea surface and has a strong marine phytoplanktonic origin. Once in the atmosphere, DMS is photo-oxydized to form sulfate aerosol particles, which may affect the radiative budget as precursors of cloud condensation nuclei (CCN).

Jones et al. (2001) recently obtained a value of $-1.9 \mathrm{~W} \mathrm{~m}^{-2}$ for the effect of anthropogenic sul-

\footnotetext{
*Corresponding author. e-mail: bopp@1sce.saclay.cea.fr.
}

fate aerosol on cloud albedo and on precipitation efficiency (the indirect sulfate aerosol forcing effect). They demonstrated in a sensitivity test that doubling oceanic DMS emission fluxes reduced this indirect effect by over $25 \%$. Thus, changes in marine DMS emissions appear to significantly affect estimates of the magnitude of sulfate aerosol forcing.

The sea-to-air flux of DMS is controlled by the DMS concentration at the sea surface and by the magnitude of the DMS transfer velocity accross the air-sea interface. The last two terms are strongly dependent on climate variables. Sea-to-air transfer velocity mainly varies with sea-surface temperature and wind velocity (Liss and Merlivat, 1986; Wanninkhof, 1992). Sea-surface DMS concentration is also regulated by 
climate variables such as solar irradiance, sea-surface temperature and ocean physics, through their control on the marine biology.

It has been postulated that the Earth's climate is partly regulated by variations in DMS emissions through a DMS-CCN-albedo feedback (Charlson et al., 1987). However, there are large uncertainties both on the sign and on the magnitude of this feedback (Liss et al., 1994).

Parameterizations of DMS production, including biological aspects of the production and removal of DMS, have been incorporated in regional models (Gabric et al., 1993) and used to estimate the potential radiative impact of changes in marine DMS emissions for the 21st century (Gabric et al., 1998; 2001). Based on a $10^{\circ} \times 20^{\circ}$ area in the Subantarctic Southern Ocean, south of Australia, Gabric et al. (2001) estimate an increase in DMS emissions of 5\% by 2080 (corresponding to equivalent $\mathrm{CO}_{2}$ tripling relative to pre-industrial levels). With this modest increased percentage, they find a small negative radiative impact, which, they conclude, confirms the minor role for DMS-derived aerosols in climate regulation. This study is essentially a regional one, and it is difficult to extend such results to the world ocean. The work of Gabric et al. (2001) is a first step towards the use of general circulation models together with DMS production models to investigate the response of DMS emissions to climate change. However, these mechanistic parameterizations are not yet suitable for global ocean models mainly because they increase computing time and cost.

In a previous paper (Aumont et al., 2002), a model of the global distribution of sea-surface DMS concentrations was presented. The DMS parameterizations proposed are not based on mechanistic equations but are based on non-linear relationships which relate DMS to the chlorophyll $a$ content of surface waters and to the food-web structure of the ecosystem (trophic state), and thus are suitable for global study. These relationships have been inferred from data made during several cruises and enable us to examine the potential impact of simulated transient climate change on global and regional marine DMS concentrations and emissions.

The transient climate response to increased atmospheric $\mathrm{CO}_{2}$ was obtained from simulations with the Institut Pierre-Simon Laplace Coupled Model 1 (IPSL-CM1) coupled ocean-atmosphere general circulation model (OAGCM) (Barthelet et al., 1998). This transient climate was then used to force a marine biogeochemical scheme and to predict the evolution of marine biology (Bopp et al., 2001). Finally, param- eterizations of DMS, as non-linear functions of the phytoplankton biomass and the trophic state of the ecosystem (Aumont et al., 2002), were applied to predict DMS sea-water concentrations and air-sea fluxes.

\section{Method}

\subsection{Climate and biogeochemical models}

The transient climate simulation was obtained from simulations with the IPSL-CM1 coupled oceanatmosphere model (Barthelet et al., 1998). The horizontal resolution of the atmospheric model is $5.6^{\circ}$ in longitude and varies as the sine of the latitude, with a mean grid spacing of $3.6^{\circ}$ in latitude. The atmospheric component has 15 vertical levels. The oceanic component, Océan PArallélise (OPA), solves the primitive equations of motion on a curvilinear mesh which has a resolution roughly equivalent to a geographic mesh of $2 \times 1.5^{\circ}$ (Madec and Imbard, 1996). The meridional resolution is higher at the Equator $\left(0.5^{\circ}\right)$ to take into account its enhanced dynamics. It has 30 vertical levels, ten are in the first $100 \mathrm{~m}$ and the deepest reaches $5000 \mathrm{~m}$. The oceanic and atmospheric components of the OAGCM are coupled through the coupler OASIS (Terray et al., 1995), which ensures the time synchronization of the two parts of the OAGCM and performs the spatial interpolation of the coupling fields from one grid to another, without flux corrections techniques. The transient climate run used in this study consists of global warming scenario in which atmospheric $\mathrm{pCO}_{2}$ was increased from $350 \mathrm{ppm}\left(1 \times \mathrm{CO}_{2}\right)$ at a rate of $1 \%$ per year, reaching $2 \times \mathrm{CO}_{2}$ after around 70 yr. A control experiment was also performed and used a constant $\mathrm{CO}_{2}$ concentration of $350 \mathrm{ppm}$. These coupled simulations were made in the context of the Coupled Model Intercomparison Project II (CMIP II) of WCRP/CLIVAR.

This transient climate was then used to force a marine biogeochemical model and to predict the evolution of marine biology (Bopp et al., 2001). The biogeochemical scheme used here is a Nutrient Phytoplankton Zooplankton and Detritus (NPZD) type model (Aumont et al., 2002). Phytoplankton growth depends on the local conditions of light, temperature and turbulence, and considers $\mathrm{PO}_{4}^{3-}$ as the only limiting nutrient. The chlorophyll content is also explicitly diagnosed using the relationship of Doney et al. (1996) to compute the carbon:chlorophyll $(\mathrm{C} / \mathrm{Chl})$ ratio of phytoplanktonic cells. Moreover, the model includes 
a simple representation of the silicon cycle following Maier-Reimer (1993). This biogeochemical model has been validated against remote sensing observations both for climatological patterns of surface chlorophyll (Aumont et al., 2002) and for interannual variability. The use of this model in a climate change scenario is a first attempt to predict the global marine ecosystem response to global warming. Results, mechanisms and uncertainties of that response, including comments on the non-consideration of other limiting elements such as iron or silica, are described in more detail in Bopp et al. (2001).

\subsection{DMS parameterizations}

Parameterizations of DMS, as non-linear functions of the phytoplankton biomass and the trophic state of the ecosystem (Aumont et al., 2002), were applied to predict DMS sea-water concentrations and air-sea fluxes from $1 \times \mathrm{CO}_{2}$ to $2 \times \mathrm{CO}_{2}$. Those relationships have been established from datasets obtained during several cruises carried out in contrasted areas of the world oceans [see Aumont et al. (2002) for details].

First, dimethyl sulfoniopropionate (DMSP), the main precursor compound of DMS, is derived from surface chlorophyll concentrations and information on species distribution. The production of DMSP by phytoplankton (particulate DMSP or pDMSP) is highly dependent on the phytoplankton species (diatoms are poor pDMSP producers whereas non-siliceous species are greater $\mathrm{pDMSP}$ producers). To characterize the proportion of diatoms within the phytoplankton community, Claustre (1994) defined a trophic status ratio, the $F p$ ratio, as the ratio of fucoxanthin and peridinin, which are characteristic pigments of diatoms and dinoflagellates, to total pigments. Our pDMSP-Chl relationship uses this $F p$ ratio to estimate the partition between siliceous (diatoms) and non-siliceous species with a higher $F p$ ratio indicating a lower fraction of pDMSP-producing phytoplankton. The diagnosis of pDMSP from chlorophyll a (Chla) modulated by the $F p$ ratio is as follows:

$$
\begin{aligned}
& \operatorname{pDMSP}=(20 \times \text { Chla } \times F p) \\
& \quad+\left(13.64+\frac{0.10769}{[1+24.97 \text { Chla }(1-F p)]^{-2.5}}\right) .
\end{aligned}
$$

A linear relationship was used to estimate the contribution of diatoms to pDMSP [first right-hand term of eq. (1)]. A ratio of $20 \mathrm{mmol} \mathrm{g}^{-1}$ was suggested to be typical of phytoplankton communities dominated by diatoms (Aumont et al., 2002) and is consistent both with determinations performed in the Antarctic ocean (Turner et al., 1995) and with the culture work of Keller and Korjeff-Bellows (1996). For the remaining phytoplankton communities (not dominated by diatoms), a non-linear function best accounts for the relationship between non-diatom chlorophyll and pDMSP. A statistical analysis of the chosen parameterization [second right-hand term of eq. (1)], obtained with a nonlinear regression technique, shows a good significance $\left(n=189, R^{2}=0.84\right.$ and $\left.\chi^{2}=22.4\right)$.

Second, the DMS:pDMSP ratio is also derived from the $F p$ ratio. Aumont et al. (2002) found a significant correlation between these two ratios $\left(n=125, R^{2}=\right.$ 0.51 and $\chi^{2}=47.4$ ), the best-fit relationship (obtained with a non-linear regression technique) being:

$$
\begin{aligned}
\frac{\mathrm{DMS}}{\mathrm{pDMSP}} & =0.015316+\frac{0.005294}{0.0205+F p} \\
& \text { for } \quad F p<0.6 \\
& =0.674 \times F p-0.371 \text { for } \quad F p>0.6 .
\end{aligned}
$$

Finally, from those two equations (1 and 2), DMS can be deduced only from a trophic status ratio $(F p)$ and the chlorophyll concentration (Chla) of surface sea waters. These relations are strongly non-linear, as expected from previous studies which have failed to derive a linear empirical relation, globally valid, between DMS and other easily measured parameters (e.g. chlorophyll, temperature, nutrients) (Kettle et al., 1999). Here, the latter parameters ( $F p$ and Chla) are estimated from the biogeochemical model results, directly for the chlorophyll content, indirectly for the $F p$ ratio. As the model does not include any explicit speciation of phytoplankton, this $F p$ ratio is not directly predicted. Aumont et al. (2002) have shown that the $\mathrm{Si}$ ratio, computed in the model as the ratio of the local simulated production to the maximum production of biogenic silica, may be considered as a proxy of the $F p$ ratio. The $S i$ ratio estimates the partitioning between non-siliceous and siliceous phytoplankton species and thus increases with the abundance of diatoms as does the $F p$ ratio. Comparisons of both ratios along the ALBATROSS cruise transect (Belviso et al., 2000) have shown a reasonable aggreement between the two ratios (Aumont et al., 2002). The silica ratio is thus substituted to the $F p$ ratio $(S i$ ratio $=F p$ ratio) in eqs. (1) and (2) to diagnose DMS and pDMSP in the model. 


\section{Comparison to data}

\subsection{Chlorophyll}

Data obtained from remote sensing by NASA's Seaviewing Wide Field-of-view Sensor (SeaWiFS) provide the means to validate the model surface distribution. Figures $1 \mathrm{a}$ and $1 \mathrm{~b}$ show the simulated and satellite-derived distributions of chlorophyll at the sur-

a)
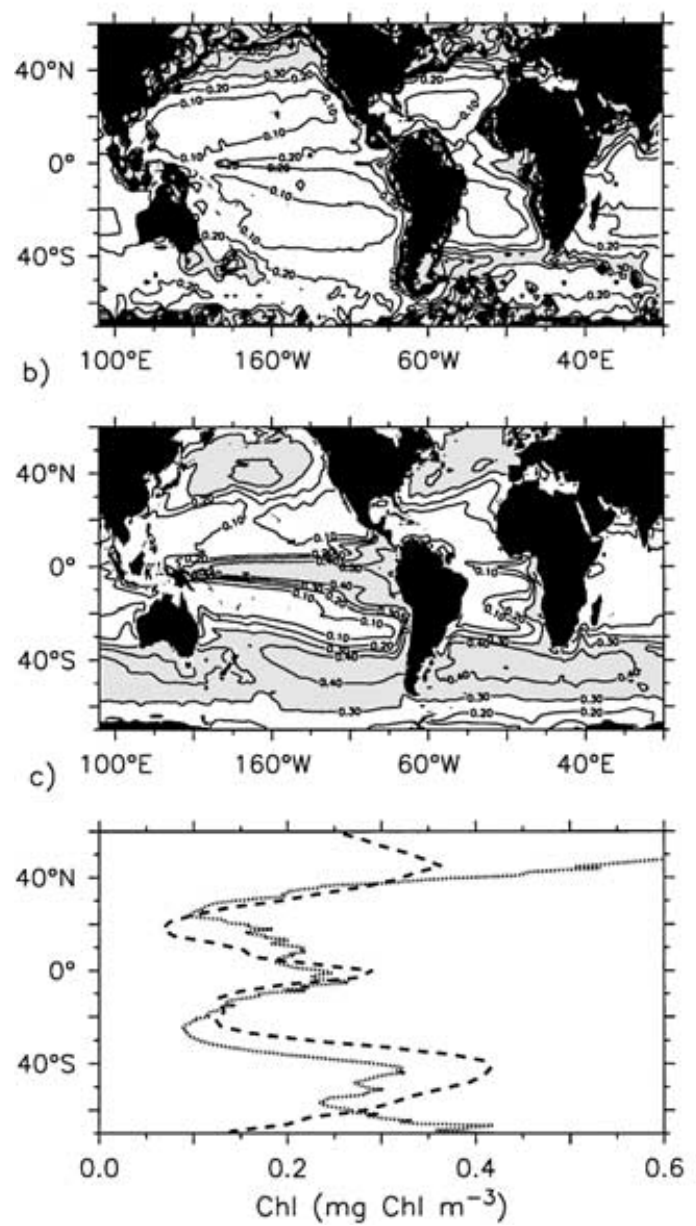

face for the annual mean. In order to compare these two chlorophyll distributions better, the zonal means are also shown (Fig. 1c). Globally, the simulated patterns generally match those which are observed. Concentrations below $0.1 \mathrm{mg} \mathrm{Chl} \mathrm{m}{ }^{-3}$ are found in the oligotrophic gyres both in the model and the observations. In the high latitudes of the Northern Hemisphere, the model predicts high concentrations $(>0.4 \mathrm{mg} \mathrm{Chl}$ $\mathrm{m}^{-3}$ for the annual mean), but fails to reproduce the

d)
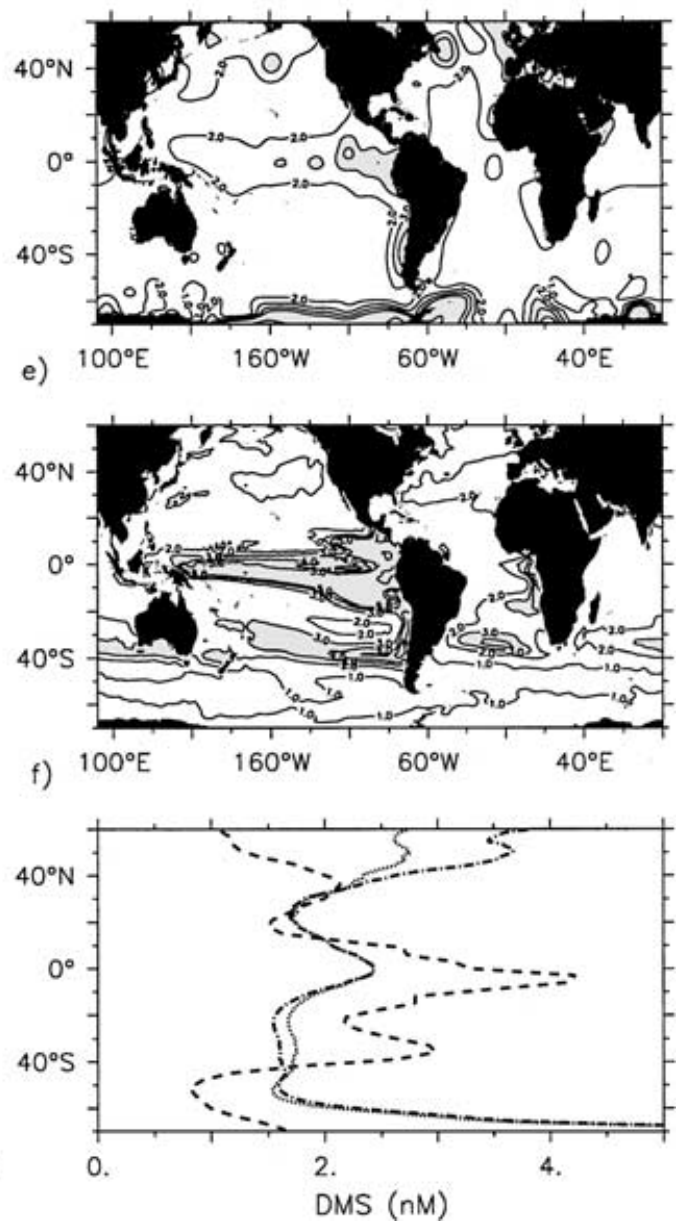

Fig. 1. Annual mean of surface chlorophyll (in $\mathrm{mg} \mathrm{m}^{-3}$ ) (a) derived from remote sensing (SeaWiFS) and (b) from our control simulation. Isolines are every $0.1 \mathrm{mg} \mathrm{Chl} \mathrm{m}{ }^{-3}$. Shaded areas denote regions where chlorophyll is higher than $0.3 \mathrm{mg} \mathrm{m}^{-3}$. (c) Zonal means of simulated (dashed line) and satellite-derived (dotted line) surface chlorophyll distributions (in $\mathrm{mg} \mathrm{m}^{-3}$ ). For the zonal mean of the satellite-derived chlorophyll, we have excluded coastal points. Annual mean of DMS concentration (in $\mathrm{nM}$ ) at the sea-surface (d) from the climatology proposed by Kettle and Andreae (2000), and (e) from our control simulation. Isolines are every 1 from 0 to 5 , every 5 from 5 to 30. Shaded areas denote regions where DMS is higher than $3 \mathrm{nM}$. (f) Zonal means of DMS concentrations predicted by the model (dashed line), and from the climatologies of Kettle et al. (1999) (dot-dashed line) and Kettle and Andreae (2000) (dotted line). 


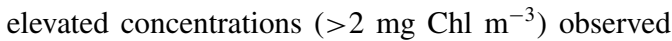
in the shelf areas, especially in the North Atlantic. This defect is particularly obvious on the zonal mean plot (Fig. 1c). However, annual mean values obtained from satellite data at those latitudes are questionable. Because of low incident irradiance in winter, the annual mean chlorophyll concentrations are biased towards the high summer values. In the equatorial Pacific ocean, the predicted chlorophyll concentrations are overestimated. Observations show concentrations of $\sim 0.1-0.3 \mathrm{mg} \mathrm{Chl} \mathrm{m}{ }^{-3}$, while in the model they exceed $0.4 \mathrm{mg} \mathrm{Chl} \mathrm{m} \mathrm{m}^{-3}$. However, the equatorial Pacific is an HNLC (high nutrient low chlorophyll) region. In situ experiments have demonstrated that biological activity is iron limited in this region (Coale et al., 1996), which may explain the paradox of this area (high nutrient levels but low chlorophyll concentrations). Our model does not include iron-limitation, which may explain why we clearly overestimate chlorophyll in this region. Our model also exhibits the same defects in other HNLC regions (North Pacific, Southern Ocean).

\section{2. $D M S$}

Kettle and Andreae (2000) have proposed a global monthly mean climatology of surface DMS, constructed from almost 17000 DMS measurements. These data were assembled using the scheme of Conkright et al. (1994) to create an annual mean surface map of DMS. However, this map should be considered with caution because of the scarcity of data, especially in the Southern Ocean, and because most measurements made at high latitudes were collected during summer. Those sampling biases introduce uncertainties that can affect the data-based map. Kettle and Andreae (2000) have shown that introducing new data points may create important fluctuations in the climatology. From the previous version of the climatology (Kettle et al., 1999) to the updated one (Kettle and Andreae, 2000), it is particularly the case at high latitudes in the Northern Hemisphere and in the Indian Ocean. Measurements from Belviso et al. (2000) and Sciare et al. (1999), added in the Kettle and Andreae (2000) version, have significantly reduced or increased (by up to $\pm 50 \%$ ) the data-based DMS concentrations in those regions [see Fig. If for the comparison of Kettle et al. (1999) and Kettle and Andreae (2000) estimates]. Despite those limitations, this climatology represents a useful means to validate model results on a global scale.

This reconstructed map of sea-surface DMS concentrations show generally low concentrations in the subtropical gyres and high concentrations in the equatorial Pacific (Fig. 1d) (Kettle and Andreae, 2000). The model reproduces these features (Fig. 1e), but it overestimates DMS concentrations, especially in the subtropical/subantarctic convergence zone and in the equatorial Pacific, and underestimates DMS concentrations at high latitudes (Fig. 1f for the comparison of the zonal means).

The discrepancy in the subtropical/subantarctic convergence is difficult to quantify because the databased annual mean DMS concentration for this area is still subject to important fluctuations. From Kettle et al. (1999) to Kettle and Andreae (2000), the mean annual DMS concentration in this region has been significantly increased, which implies a better comparison with the model's predictions. Indeed, the updated database now takes into account concentrations up to $7 \mathrm{nM}$ in the convergence zone of the South Atlantic (Belviso et al., 2000) and up to $35 \mathrm{nM}$ in the convergence zone of the Indian Ocean (Sciare et al., 1999). In the equatorial Pacific ocean, modeled DMS concentrations are about twice as high as the databased concentrations. In this region, the simulated biological activity is too intense, because it does not include limitations by other nutrients such as iron or silicate. Finally, DMS concentrations at high latitudes are underestimated, especially along the Antarctic coasts, where the model does not resolve the strong blooms of Phaeocystis, a phytoplankton species that produces much DMS. However, the very high DMS concentrations in the data-based annual mean along Antarctic coasts may be due to sampling biases, since most of the measurements have been made essentially during the summer months and in the Weddel and Ross seas.

A more robust means to evaluate the model is to compare DMS fields to direct measurements. Seven different transects were chosen as representative of the major oceanic regions (Fig. 2). In the Atlantic, the model does not reproduce the mesoscale variability but captures the correct order of magnitude of the observed DMS concentrations (Figs. 2a and 2b). In particular, it succeeds in reproducing the strong zonal gradient in DMS (Andreae et al., 1994), which is due to the intense biological activity in the dome of Angola (Fig. 2b). In the South Atlantic, the model simulates high DMS levels at $30-35^{\circ} \mathrm{S}$, whereas in the data such levels are observed at $35-40^{\circ} \mathrm{S}$ (Fig. 2a). This 

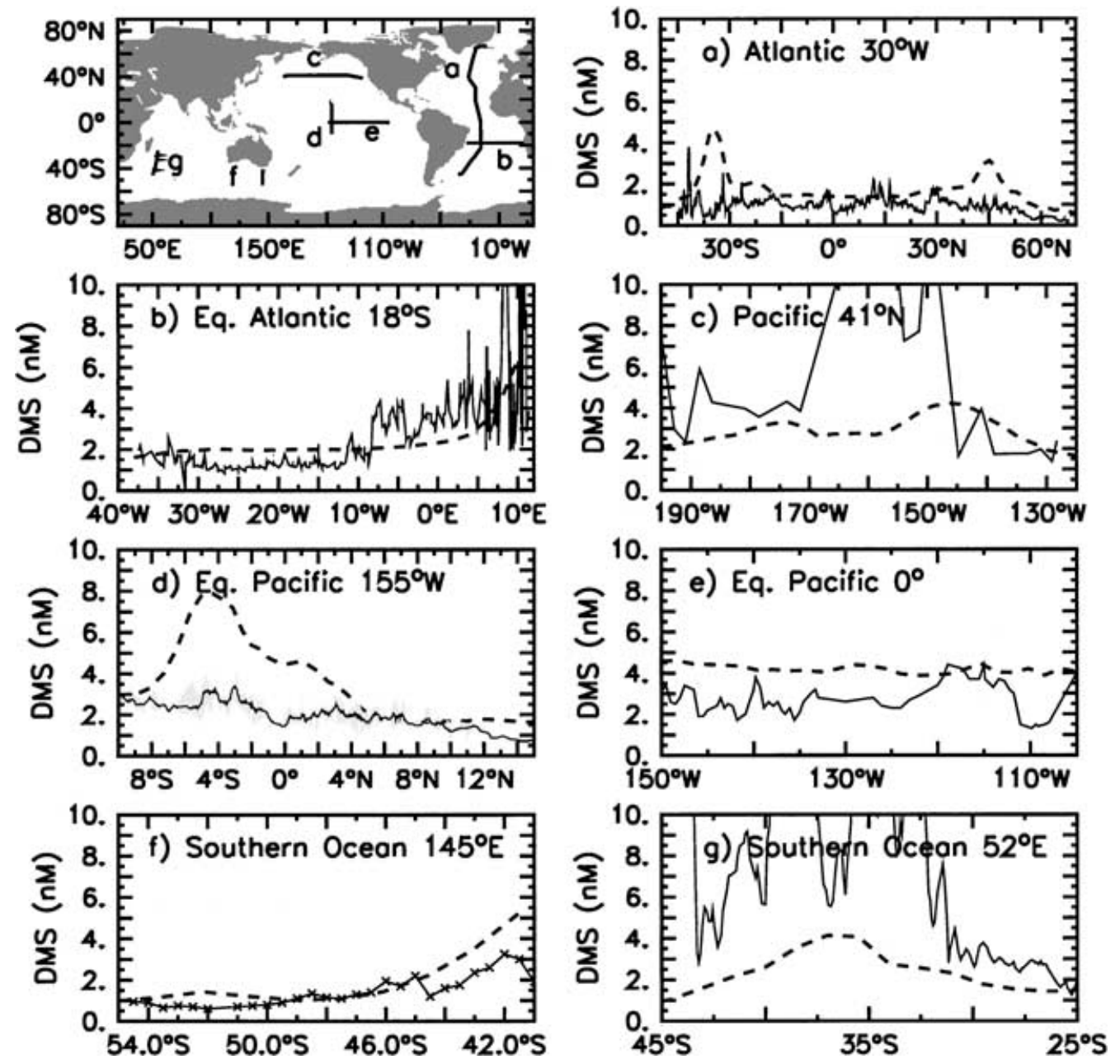

Fig. 2. Variations of surface DMS (nM) along (a) the ALBATROSS transect in October 1996 (Belviso et al., 2000), (b) $18^{\circ} \mathrm{S}$ in February-March 1991 (Andreae et al., 1994), (c) $41^{\circ} \mathrm{N}$ in August 1988 (Wanatabe et al., 1995), (d) $155^{\circ} \mathrm{W}$ in FebruaryMarch 1990 (Bates et al., 1987), (e) $0^{\circ}$ in April 1983 (Bates et al., 1987), (f) $145^{\circ} \mathrm{E}$ in November-December (Mari et al., 1998), and (g) 50-55 E in December 1997 (Sciare et al., 1999). Solid lines shows the in-situ observations and dashed line represents model results.

discrepancy originates from the representation in our model of the silica front off the Argentina Plateau, which is $10^{\circ}$ too far to the north.

In the North Pacific, the model fails in reproducing the widely varying DMS concentrations, but predicts a background level around 3-4 nM (Fig. 2c). In the Equatorial Pacific, the model simulates a decrease of DMS concentrations from $5^{\circ} \mathrm{S}$ to $15^{\circ} \mathrm{N}$ and constant levels at $0^{\circ}$ from $150^{\circ} \mathrm{W}$ to $105^{\circ} \mathrm{W}$. However, as already mentioned, our model strongly over-estimates DMS in this region (Figs. $2 \mathrm{~d}$ and $2 \mathrm{e}$ ).
In the Southern Ocean, the decrease of DMS from 40 to $50^{\circ} \mathrm{S}$ south of Tasmania (Mari et al., 1998), is reproduced by the model with the correct order of magnitude (Fig. 2f). However, when compared to data in the Indian sector of the Southern Ocean (Sciare et al., 1999), the model predicts relatively high DMS concentrations in the subtropical-subantarctic convergence zone $\left(35-40^{\circ} \mathrm{S}\right)$ but fails to reproduce such high levels as up to $15-35 \mathrm{nM}$ (Fig. $2 \mathrm{~g}$ ).

Finally, it is worth noticing that the present model cannot capture the significant patchiness occurring in 
the real ocean, for both chlorophyll and DMS concentrations. In addition, beyond the first attempt made by Kettle et al. (1999) and Kettle and Andreae (2000), the significant fluctuation of the DMS database implies the need to have much more extensive surveys to aggregate datasets in climatological sense without strong sampling biases.

\subsection{DMS flux}

The model predicts an annual mean global flux of DMS to the atmosphere of 15.4 and $26.0 \mathrm{TgS} \mathrm{yr}^{-1}$, using, respectively, the Liss and Merlivat (1986) and the Wanninkhof (1992) formulations for the gas exchange coefficient. Those values are coherent with the compilation of DMS flux estimates (Kettle and Andreae, 2000), proposing a large range of values between 15 and $33 \mathrm{TgSyr}^{-1}$ using different formulations (Liss and Merlivat, 1986; Erickson, 1993; Wanninkhof, 1992) for the gas exchange.

Direct validation of regional DMS fluxes is difficult because DMS fluxes can not yet be directly measured. An alternative way to check our modeling approach is to use atmospheric information that average DMS efflux over large areas, typically few hundreds to few thousands kilometres. Gabric et al. (2001) have reconstructed DMS fluxes from atmospheric measurements made at Cape Grim (Ayers et al., 1995). To compare our simulated DMS fluxes to this data-based estimate (Fig. 3), we have averaged our DMS fluxes over a $10^{\circ}$ latitude by $10^{\circ}$ longitude region, upwind of Cape Grim. The model reproduces the high summer values resulting from the intense biological production and the low

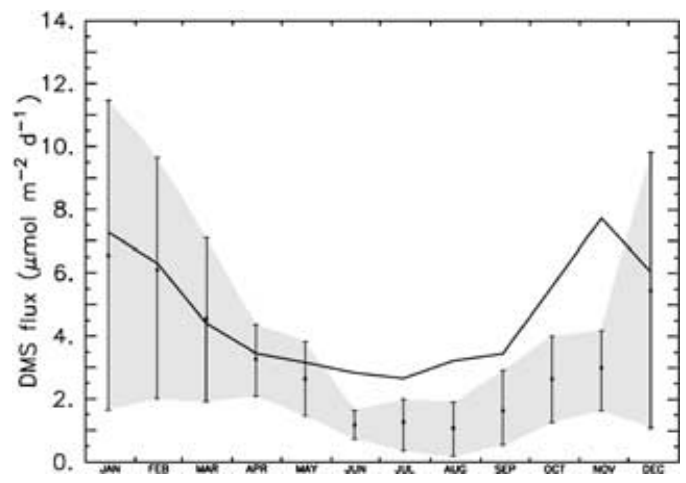

Fig. 3. Comparison of simulated DMS flux annual cycle, using the Liss and Merlivat (1986) formulation for the gas exchange (solid line, $\mu \mathrm{mol} \mathrm{m} \mathrm{m}^{-2} \mathrm{~d}^{-1}$ ) with Cape Grim databased estimates (Ayers et al., 1995). winter values. However, the simulated summer peak starts too early when compared with the data-based estimate. This suggests that the model predicts a spring phytoplankton bloom which is too early in the year.

\section{Impact of climate change}

At $2 \times \mathrm{CO}_{2}$, our model predicts a $9 \%$ global decrease in the mean annual primary production. However, it also shows opposing changes between the high and low latitudes. Climate-induced changes in the ocean decrease marine production by $20 \%$ in the low latitudes but increase production by $30 \%$ in the high latitudes. These changes are driven by two opposing mechanisms: by reduced nutrient supply and by an increased light efficiency due to a longer growing season. Changes result from increased stratification in the upper ocean (Fig. 4b). Results, mechanisms and uncertainties of the response of marine production to climate change, including comments on the non-consideration of other limiting elements such as iron or silica, are described in more detail in Bopp et al. (2001). Here, we investigate how these changes propagate up to the DMS cycle.

\subsection{DMS concentrations changes}

Changes in marine productivity lead to a small decrease of global sea-surface DMS concentrations of

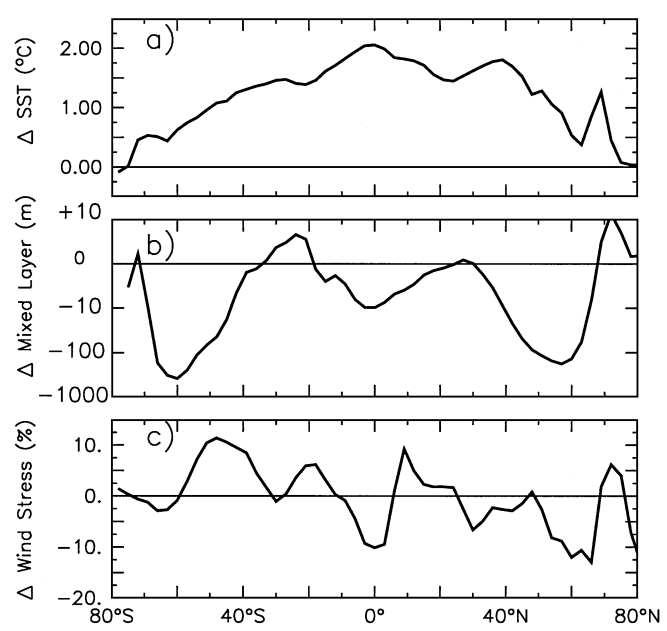

Fig. 4. Zonal means of $2 \times \mathrm{CO}_{2}$ climate change impact on (a) annual-mean SST (in ${ }^{\circ} \mathrm{C}$ ), (b) yearly maximum of the mixed layer depth (in $\mathrm{m}$ ) and (c) annual-mean wind stress (in \%). 


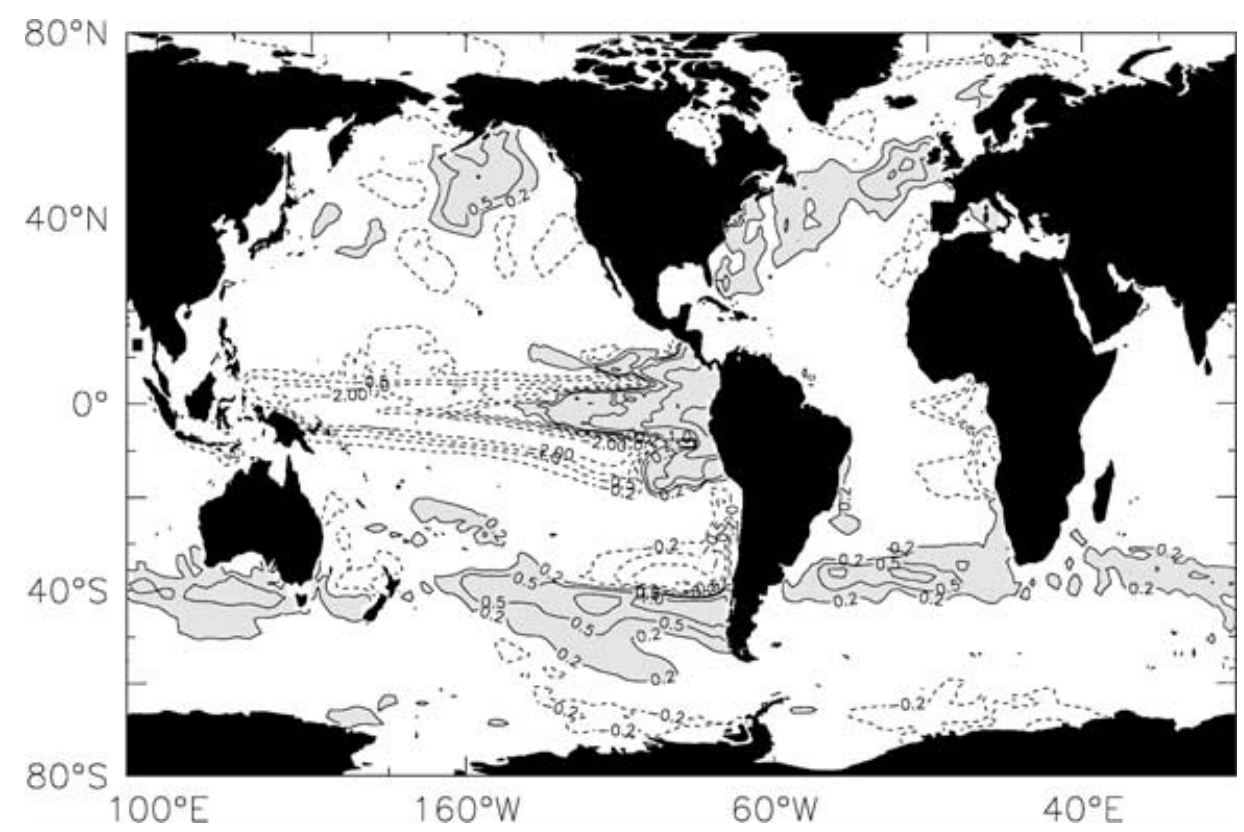

Fig. 5. Difference $\left(2 \times \mathrm{CO}_{2}-1 \times \mathrm{CO}_{2}\right)$ of the annual mean DMS concentration (in $\left.\mathrm{nM}\right)$. Isolines are every 2 from -5 to $-1,-0.5,-0.2,0.2,0.5$ and every 2 from 1 to 5 . Shaded areas denote regions where the increase in DMS concentrations is more than $0.2 \mathrm{nM}$.

about $1 \%$. As shown for the marine productivity, this very modest reduction of global mean DMS concentration conceals large spatial heterogeneities. Indeed, our model predicts an opposition between mid and low latitudes at $2 \times \mathrm{CO}_{2}$.

Tropical latitudes are depleted in sea surface DMS up to $5 \mathrm{nM}(-50 \%)$ in the west equatorial Pacific and the east equatorial Atlantic (Fig. 5), and up to $0.5 \mathrm{nM}$ $(-10 \%)$ for the zonal mean (Fig. 6d). Nevertheless, the east equatorial Pacific shows a rather strong enrichment in sea-surface DMS, up to $5 \mathrm{nM}(+50 \%)$. On the other hand, the subtropical/subantarctic convergence zone exhibits an enrichment in sea-surface DMS, up to $0.5 \mathrm{nM}(+20 \%)$ for the zonal mean at $40-50^{\circ} \mathrm{S}$ (Fig. 6d). The North Atlantic and North Pacific also exhibit this strong DMS enrichment (up to $1 \mathrm{nM}$ ).

Changes in sea-surface DMS concentrations are caused by either changes in the total phytoplankton biomass or changes in the trophic state of the ecosystem. At low latitudes, and except for the eastern equatorial Pacific, changes in DMS concentrations are linked to changes in the phytoplankton biomass. At $2 \times \mathrm{CO}_{2}$, the model predicts a decrease of nutrient supply to the euphotic zone because of enhanced stratification and decreased intensity of
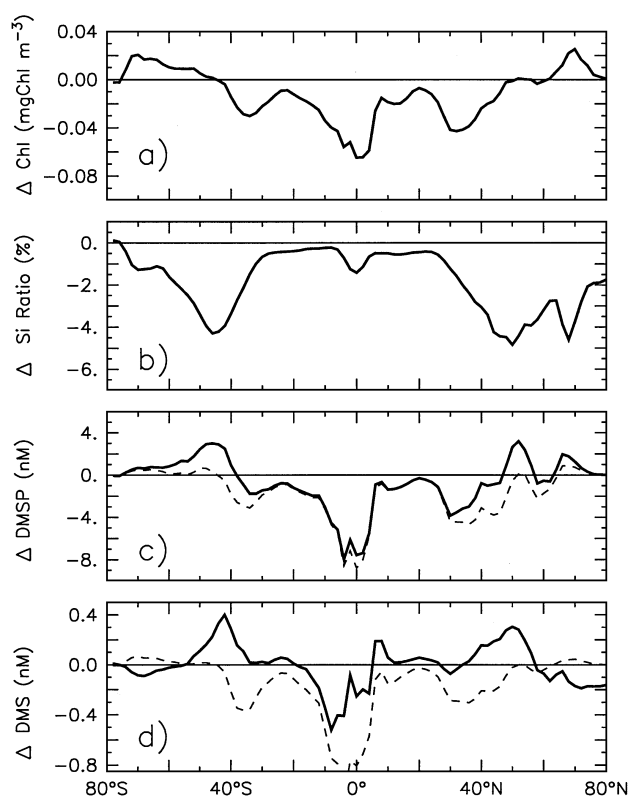

Fig. 6. Zonal means of $2 \times \mathrm{CO}_{2}$ climate change impact on (a) chlorophyll, (b) Si ratio, (c) surface pDMSP and (d) surface DMS. Dashed curves in panels (c) and (d) are zonal means impact of $2 \times \mathrm{CO}_{2}$ chlorophyll changes on (c) pDMSP and (d) DMS at a constant Si ratio. 
tropical upwellings (Bopp et al., 2001). Consequently, marine productivity and surface chlorophyll concentrations are lower at $2 \times \mathrm{CO}_{2}$. The reduction in chlorophyll content even reaches $0.15 \mathrm{mg} \mathrm{Chl} \mathrm{m}^{-3}(-50 \%)$ in the western equatorial Pacific and $0.08 \mathrm{mgChl} \mathrm{m}^{-3}$ for the zonal mean in the tropical band (Fig. 6a). This decrease leads to a lower abundance in pDMSP and in DMS, as shown by the dashed lines in Fig. 6c (for pDMSP) and Fig. 6d (for DMS).

In the Southern Ocean and the eastern equatorial Pacific, changes in DMS concentrations are linked to changes in the trophic state of the ecosystem. Our model shows a retreat of siliceous species (mainly diatoms), and their replacement by non-siliceous species both in the Southern Ocean, in the North Pacific and North Atlantic, and in the eastern equatorial Pacific (Fig. 7). In those regions, the $\mathrm{Si}$ ratio decreases because of sea-surface warming (up to $2.5{ }^{\circ} \mathrm{C}$ in the eastern equatorial Pacific) and a decrease in surface silicate concentration (up to $10 \mu \mathrm{mol} \mathrm{L} \mathrm{L}^{-1}$ at $40-50^{\circ} \mathrm{S}$ ). This decrease (Fig. 7), up to $5 \%$ for the zonal mean (Fig. 6c), mimics a retreat of siliceous species. Simulations with an ecosystem model that explicitly includes nanophytoplankton and diatoms, as well as $\mathrm{Fe}, \mathrm{Si}$ and $\mathrm{P}$ co-limitations, show a similar response to climate change (Bopp, 2001). In both cases, diatom-dominated ecosystems are shifted towards the pole and replaced by non-siliceous species.

Despite relatively constant chlorophyll levels, the shift from siliceous to non-siliceous species, which are greater pDMSP producers, explains the pDMSP increase in the $40-60^{\circ}$ band in both hemispheres (Fig. 6c) and part of the DMS enhancement (Fig. 6d). Secondly, this $S i$ ratio reduction causes an increase of the DMS:pDMSP ratio, in the eastern equatorial Pacific and in the $30-50^{\circ} \mathrm{S}$ and $30-50^{\circ} \mathrm{N}$ bands, contributing significantly to this DMS enrichment (Fig. 6d).

In summary, DMS enrichment at mid-latitudes is caused by changes in the community structure of the ecosystem (less diatoms), and DMS reduction at low latitudes is caused by the decrease of the total phytoplankton biomass.

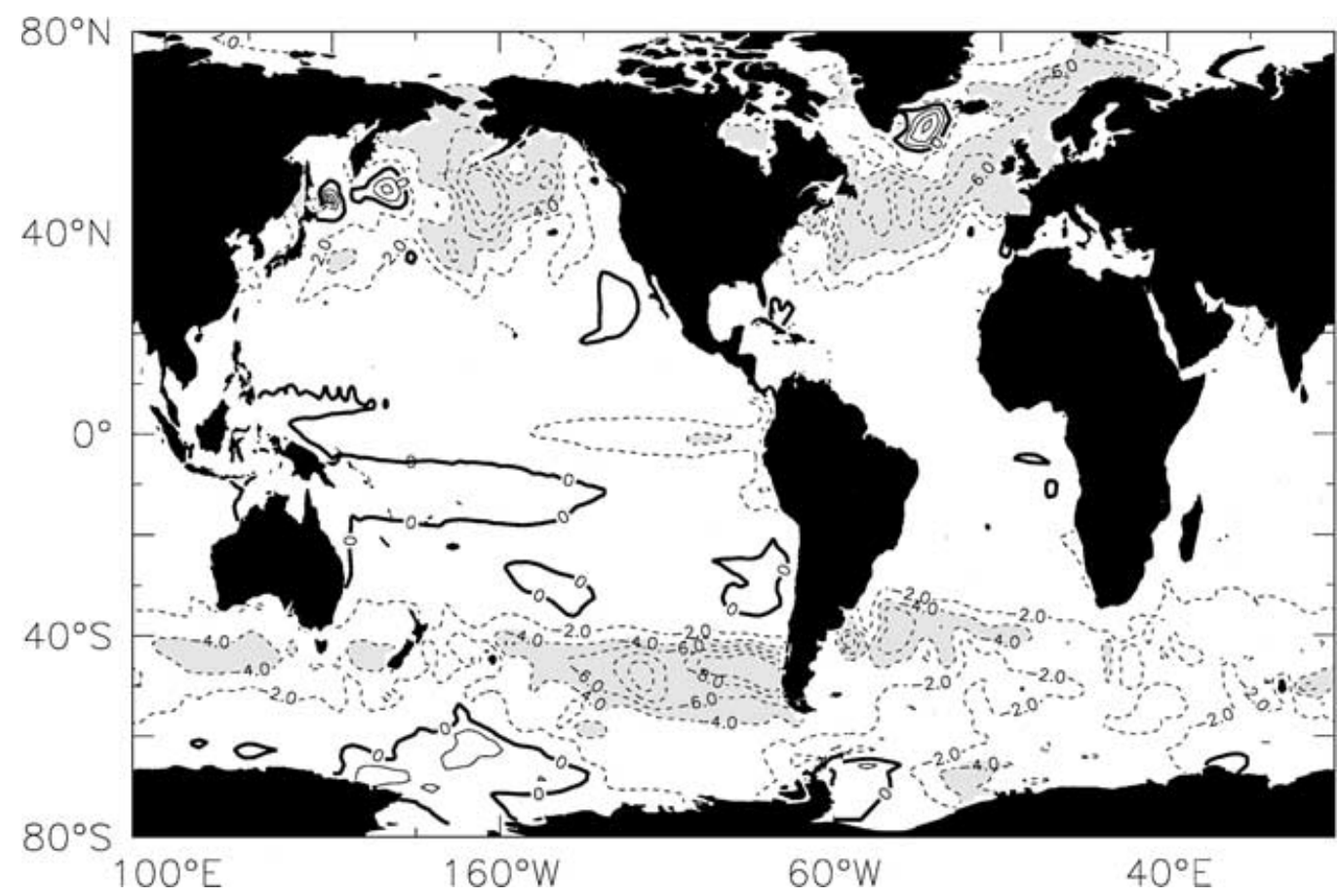

Fig. 7. Difference $\left(2 \times \mathrm{CO}_{2}-1 \times \mathrm{CO}_{2}\right)$ of the relative abundance of siliceous phytoplankton (diatoms) to total phytoplankton. Contours are every $2 \%$ from -10 to $+10 \%$. Shaded areas denote regions where the decrease in diatoms abundance is more than $4 \%$.

Tellus 55B (2003), 1 


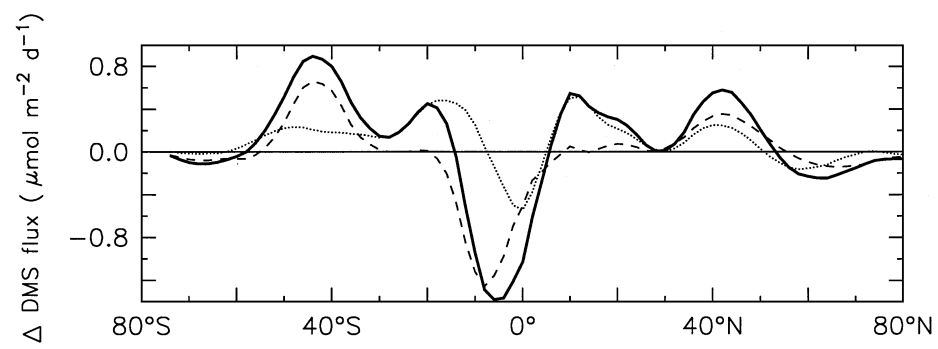

Fig. 8. Zonal mean of $2 \times \mathrm{CO}_{2}$ climate change impact on DMS flux in $\mu \mathrm{mol} \mathrm{m}{ }^{-2}$ day $^{-1}$ (solid line), using Liss and Merlivat (1986) relationship for the transfer velocity. Also shown are the effects of wind changes alone (dotted line) and DMS concentration changes alone (dashed line).

\subsection{DMS fluxes changes}

At $2 \times \mathrm{CO}_{2}$, the global DMS flux to the atmosphere is increased by about $2 \%$, which supports the minor role of DMS for future climate change. This modest global figure, however, conceals a large spatial heterogeneity. In the tropical Pacific, the DMS fluxes [using the Liss and Merlivat (1986) relationship] are reduced by up to $10 \mu \mathrm{mol} \mathrm{m} \mathrm{m}^{-2} \mathrm{~d}^{-1}(-60 \%)$. Conversely, in the subtropical and subantarctic zone, DMS fluxes are strongly enhanced by up to $5 \mu \mathrm{mol} \mathrm{m} \mathrm{m}^{-2}$ $\mathrm{d}^{-1}(+50 \%)$. These regional changes and the latitudinal opposition are driven by variations in DMS concentrations, but stronger winds in the Southern Ocean and weaker winds in the equatorial region at $2 \times \mathrm{CO}_{2}$ (Fig. 4c) even amplify the large heterogeneity (Fig. 8).

In the $30-50^{\circ} \mathrm{S}$ band the model predicts a, $19 \%$ increase in the annual DMS flux (from 2.7 to $3.2 \mathrm{TgS}$ $\mathrm{yr}^{-1}$ ). The effect of wind changes alone accounts for one quarter of the total increase $(\mathrm{a}+5 \%$ increase), whereas the major effect is driven by changes in sea-surface DMS concentrations $(+15 \%)$. Changes in DMS concentrations in that region result mainly from modifications of the community structure of the ecosystem (shift from diatoms to non-siliceous species).

In the subantarctic southern ocean, Gabric et al. (2001) also predict an increase in DMS flux by 2080, but their increase $(+5 \%)$ is four times lower than our predicted number $(+19 \%)$. The difference may be explained by the fact that they do not consider large-scale changes in the nutrient distribution of the euphotic zone nor changes in the trophic state of the ecosystem. Our results indicate that such processes (species shift) are of particular relevance for predictions of DMS flux response to climate change.
The variations in DMS flux could affect climate, in particular in the unpolluted marine atmosphere of the subantarctic Southern Ocean. Using the Gabric et al. (1998) approach, we have crudely estimated the potential radiative impact of our simulated changes in DMS fluxes. At $2 \times \mathrm{CO}_{2}$, this impact ranges from $-1 \mathrm{~W} \mathrm{~m}^{-2}$ in the Southern Ocean to $0.5 \mathrm{~W} \mathrm{~m}^{-2}$ in the tropical regions. Thus, predicted changes in DMS fluxes could impact significantly on regional temperature and precipitation patterns.

\section{Conclusion}

Future climate changes are likely to affect the ocean circulation and, the marine biological productivity which in turn affect the marine sulfur cycle. Here, using (1) a coupled ocean-atmosphere model forced by increasing atmospheric $\mathrm{CO}_{2},(2)$ a marine biogeochemical scheme and (3) data-based parameterizations of sea-surface pDMSP and DMS, we estimate the impact of future climate change on DMS fluxes to the atmosphere. At $2 \times \mathrm{CO}_{2}$, DMS efflux (15.5-26.0 TgS $\left.\mathrm{yr}^{-1}\right)$ is similar to the $1 \times \mathrm{CO}_{2}$ value $(15.3-25.4 \mathrm{TgS}$ $\left.\mathrm{yr}^{-1}\right)$; however, we found large regional contrasts. The main results are a reduction of this flux in the tropical band $(-15 \%)$ and an increase in the mid-latitudes of both hemispheres $(+30 \%)$. These regional changes are mainly driven by a chlorophyll decrease at low latitudes and shift of phytoplankton species (from diatoms to other species more efficient in producing DMS) at mid-latitudes. These large variations could affect climate, regional temperature and precipitation patterns, in particular in the unpolluted marine atmosphere of the Southern Ocean.

The enhanced DMS production we predict in the Antarctic ocean is consistent with previous studies 
(Gabric et al., 1998; 2001) that predicted such an increase with different method and models. However, our results strongly depend on the skill of our model to simulate marine productivity and on the relationships we use to predict DMS from biological variables. Improvements in both aspects will be necessary to develop greater confidence in such future predictions. An intermediate checking step would be to explain the role of climate variability on interannual DMS variations (Sciare et al., 2000).

\section{Acknowledgments}

We thank C. Le Quéré and two anonymous reviewers for useful comments. This work was funded by the Environment and Climate Programme of the European Community (IRONAGE contract EVK21999-00227) and supported also by the French national programme PROOF of CNRS/INSU. Support for computations was provided by CNRS/IDRIS under project 010040 .

\section{REFERENCES}

Andreae, T. W., Andreae, M. O. and Sehebeske, G. 1994. Biogenic sulfur emissions and aerosols over the tropical south atlantic 1. Dimethylsulfide in seawater and in the atmospheric boundary layer. J. Geophys. Res. 99, 22819 22829.

Aumont, O., Belviso, S. and Monfray, P. 2002. Dimethylsulfoniopropionate (DMSP) and dimethyl sulfide (DMS) sea surface distributions simulated from a global 3-D ocean carbon cycle model. J. Geophys. Res. (in press).

Ayers, G. P., Ivey, S. T. B. and Frogan, B. W. 1995. Dimethyl sulfide in marine air at Cape Grim, 41S. J. Geophys. Res. 100, $21013-21021$.

Barthelet, P., Bony, S., Braconnot, P., Braun, A., Cariolle, D., Cohen-Solal, E., Dufresne, J.-L., Delecluse, P., Déqué, M., Fairhead, L., Filiberti, M.-A., Forichon, M., Grandpeix, J.-Y., Guilyardi, E., Houssais, M.-N., Imbard, M., Treut, H. L., Lévy, C., Li, Z., Madec, G., Marquet, P., Marti, O., Planton, S., Terray, L., Thual, O. and Valcke, S. 1998. Simulations couplées globales des changements climatiques associés à une augmentation de la teneur atmosphérique en $\mathrm{CO}_{2}$. C. R. Acad. Sci. Paris 326, 677684.

Bates, T. S., Cline, J. D., Gammon, R. H. and Kelly-Hansen, S. R. 1987. Regional and seasonal variations in the flux of dimethylsulfide to the atmsophere. J. Geophys. Res. 92, 2930-2938.

Belviso, S., Morrow, R. and Mihalopoulos, N. 2000. An atlantic meridional transect of surface water dimethyl sulfide concentrations with $10-15 \mathrm{~km}$ horizontal resolution and close examinations of ocean circulation. J. Geophys. Res. 105, 14 423-14431.

Bopp, L. 2001. Changements climatiques et biogéochimie océanique. Ph.D. thesis, Université Paris VI, Paris, France.

Bopp, L., Monfray, P., Aumont, O., Dufresne, J.-L., LeTreut, H., Madec, G., Terray, L. and Orr, J. 2001. Potential impact of climate change on marine export production. Global Biogeochem. Cycles 15, 81-99.

Charlson, R. J., Lovelock, J. E., Andreae, M. O. and Warren, S. G. 1987. Oceanic phytoplankton, atmospheric sulphur, cloud albedo and climate. Nature 326, 655661 .
Claustre, H. 1994. The trophic status of various oceanic provinces as revealed by phytoplankton pigment signatures. Limnol. Oceanogr. 39, 1206-1210.

Coale, K., Johnson, K., Fitzwater, S., Gordon, R., Tanner, S., Chavez, F., Ferioli, L., Sakamoto, C., Rogers, P., Millero, F., Steinberg, P., Nightingale, P., Cooper, D., Cochlan, W., Landry, M., Constantinou, J., Rollwagen, G., Trasvina, A. and Kudela, R. 1996. A massive phytoplankton bloom induced by an ecosystem-scale iron fertilization experiment in the equatorial Pacific Ocean. Nature 383, 495501 .

Conkright, M. E., Levitus, S. and Boyer, T. P. 1994. NOAA Atlas NESDIS 1: World ocean atlas, 1994, vol. 1, Nutrients. Tech. Rep., Natl. Oceanic and Atmos. Admin., Silver Spring, Md.

Doney, S. C., Glover, D. M. and Najjar, R. G. 1996. A new coupled one-dimensional biological-physical model for the upper ocean: Applications to the JGOFS Bermuda Atlantic Time-series Study (BATS) site. Deep Sea Res. 43, 591-624.

Erickson, D. J. I. 1993. A stability dependent theory for airsea gas exchange. J. Geophys. Res. 95, 7543-7552.

Gabric, A. J., Murray, N., Stone, L. and Kohl, M. 1993. Modelling production of dimethylsulfide during a phytoplankton bloom. J. Geophys. Res. 98, $22805-$ 22816.

Gabric, A. J., Whetton, P. H., Boers, R. and Ayers, G. P. 1998. The impact of simulated climate change on the air-sea flux of dimethylsulphide in the subantarctic southern ocean. Tellus 50B, 388-399.

Gabric, A. J., Whetton, P. H. and Cropp, R. 2001. Dimethylsulphide production in the subantarctic southern oceani under enhanced greenhouse conditions. Tellus 53B, 273287

Jones, A., Roberts, D., Woodage, M. and Johnson, C. 2001. Indirect sulphate aerosols forcing in a climate model with an interactive sulphur cycle. J. Geophys. Res. 106, 2029320310.

Keller, M. D. and Korjeff-Bellows, W. 1996. Physiological aspects of the production of dimethylsulfoniopropionate (DMSP) by marine phytoplankton. In: Biological 
environmental chemistry of DMSP and related sulfonium compounds. (Eds. R. P. Kiene, P. T. Visscher, M. D. Keller and G. O. Kirst), Plenum Press, New York 131153.

Kettle, A. J. and Andreae, M. 2000. Flux of dimethylsulfide from the oceans: a comparison of updated datasets and flux models. J. Geophys. Res. 105, 26 793-26808.

Kettle, A. J., Andreae, M. O., Amouroux, D., Andreae, T., Bates, T., Belviso, S., Berresheim, H., Bingemer, H., Boniforti, R., Curran, M. A. J., DiTullio, G. R., Helas, G., Jones, G. B., Keller, M. D., Kiene, R. P., Leck, C., Levasseur, M., Malin, G., Maspero, M., Matrai, P., McTaggart, A. R., Mihalopoulos, N., Nguyen, B. C., Novo, A., Putaud, J. P., Rapsomanikis, S., Roberts, G., Schebeske, G., Sciare, J., Sharma, S., Simo, R., Staubes, R., Turner, S. and Uherl, G. 1999. A preliminary global data base of sea surface Dimethyl Sulfide (DMS) as a function of latitude, longitude and month. Global Biogeochem. Cycles 13, 399445.

Liss, P. and Merlivat, L. 1986. Air-sea gas exchange: Introduction and synthesis. In: The role of air-sea exchange in geochemical cycling (Ed. P. Buat-Ménard), D. Reidel, Dordrecht.

Liss, P., Malin, G., Turner, S. M. and Holligan, P. M. 1994. Dimethylsulphide and Phaeocystis: a review. J. Mar. Sys. 5, 41-53.

Madec, G. and Imbard, M. 1996. A global ocean mesh to overcome the North Pole singularity. Clim. Dynam. 12, 381-388.

Maier-Reimer, E. 1993. Geochemical cycles in an ocean gen- eral circulation model: preindustrial tracer distributions. Global Biogeochem. Cycles 7, 645-677.

Mari, C., Suhre, K., Bates, T., Johnson, J., Rosset, R., Bandy, A., Eisele, F., III, R. M. and Thornton, D. 1998. Physicolchemical modeling of the First Aerosol Characterization Experiment (ACE 1) Lagrangian B 2. DMS emission, transport and oxydation at the mesoscale. J. Geophys. Res. 103, 16 457-16473.

Sciare, J., Mihalopoulos, N. and Nguyen, B. C. 1999. Summertime seawater concentrations of dimethylsulfide in the western indian ocean: Reconciliation of fluxes and spatial variability with long-term atmospheric observations. J. Atmos. Chem. 32, 357-373.

Sciare, J., Mihalopoulos, N. and Dentener, F. 2000. Interannual variability of atmospheric dimethylsulfide in the southern indian ocean. J. Geophys. Res. 105, 2636926377.

Terray, L., Sevault, E., Guilyardi, E. and Thual, O. 1995. The OASIS coupler user guide version 2.0. Tr/cmgc/9546, CERFACS, Toulouse, France.

Turner, S. M., Nightingale, P. D., Broadgate, W. and Liss, P. S. 1995. The distribution of dimethylsulphide and dimethylsulphoniopropionate in Antarctic waters and sea ice. Deep Sea Res. 42, 1059-1080.

Wanatabe, S., Yamamoto, H. and Tsunogai, S. 1995. Dimethylsulfide widely varying in surface water of the eastern North Pacific. J. Geophys. Res. 51, 253-259.

Wanninkhof, R. 1992. Relationship between wind speed and gas exchange over the ocean. J. Geophys. Res. 97, 73737382 . 